Gut, 1982, 23, 102-107

\title{
Assessment of anorectal function in selection of patients for ileorectal anastomosis in Crohn's colitis
}

\author{
M R B KEIGHLEY, * P BUCHMANN, AND J R LEE \\ From the General Hospital, Birmingham
}

SUMMARY Anorectal function has been assessed in 53 patients with Crohn's disease by measurement of resting and squeeze anal canal pressures and the maximum volume tolerated during distension of a balloon in the rectum. Radiographs of the rectum from barium enema examination were also reviewed to assess rectal capacity. Thirty-three patients have had a colectomy and ileorectal anastomosis for Crohn's colitis of whom 13 now have a stoma because they either required a protectomy $(n=9)$ or where closure of a loop ileostomy had not been possible $(n=4)$ because of severe anorectal disease. The maximum tolerated volume was less than $150 \mathrm{ml}$ in 12 of 13 patients who now have a stoma compared with none of the 20 patients who have a functioning anastomosis. Although the correlation between a radiological assessment of rectal capacity and the maximum tolerated volume was poor, a severely contracted rectum was associated with the need for a stoma in six of seven patients compared with only two of 13 patients who did not have radiological signs of a narrow rectum.

In Crohn's colitis there is often relative sparing of the rectum. ${ }^{1}$ If the patient requires an operation because of symptomatic Crohn's colitis an ileorectal anastomosis may be considered provided there is minimal rectal and perianal disease. Although the incidence of ileal or rectal recurrence and eventual proctectomy is high after ileorectal anastomosis, ${ }^{2}$ the operation is useful in younger patients who are anxious to avoid an ileostomy and the possible complications of impotence and chronic perineal sepsis after excision of the rectum. ${ }^{3}$

Conventional selection of patients for ileorectal anastomosis in Crohn's colitis includes evidence of rectal sparing on sigmoidoscopy, presence of a normal anal sphincter as judged by rectal examination, absence of severe perianal disease, and a distensible rectum as seen on barium enema. ${ }^{4}$

The aims of this study have been (1) to review the outcome of ileorectal anastomosis for Crohn's colitis; (2) to evaluate if an assessment of anorectal function would be helpful in the selection of patients for ileorectal anastomosis in Crohn's colitis; and

-Address for correspondence: M R B Keighley, The General Hospital, Steelhouse Lane, Birmingham B4 6NH.

Received for publication 8 June 1981
(3) to compare the manometric findings and clinical outcome with a radiological assessment of rectal capacity.

\section{Methods}

PATIENTS

Assessment of anorectal function has been performed in 53 patients with Crohn's disease (Table 1). Thirty-three patients treated by colectomy and ileorectal anastomosis were studied, 20 preoperatively and 13 one to eight years after operation. Of the 33 patients who had an ileorectal anastomosis nine had an initial loop ileostomy, four because of severe rectal or perianal disease, and five as a decompression $^{5}$ because the surgeon wished to protect the anastomosis. Manometric studies were also performed in another 20 patients to provide additional comparisons with the barium enema, five were treated by proctocolectomy, eight by ileal or ileocaecal resection, and seven received medical treatment alone. All patients have attended for regular follow-up. Six of the ileorectal patients have had repeated measurements of anorectal function over two to four years. 
Table 1 Patients studied

\begin{tabular}{|c|c|c|c|c|c|}
\hline & $\begin{array}{l}\text { Operation } \\
\text { dates }\end{array}$ & $\begin{array}{l}\text { Mean age } \\
(y r)\end{array}$ & Male & $\begin{array}{l}\text { Perianal } \\
\text { disease }\end{array}$ & $\begin{array}{l}\text { Maximum tolerated } \\
\text { volume } \\
\text { less than } 150 \mathrm{ml}\end{array}$ \\
\hline $\begin{array}{l}\text { 33: Ileorectal anastomosis } \\
20 \text { Preoperative studies } \\
13 \text { Postoperative* studies }\end{array}$ & $\begin{array}{l}1975-79 \\
1968-75\end{array}$ & $\begin{array}{l}36 \cdot 3 \\
35 \cdot 5 \\
36 \cdot 2\end{array}$ & $\begin{array}{r}16 \\
9 \\
7\end{array}$ & $\begin{array}{r}11 \\
6 \\
5\end{array}$ & $\begin{array}{r}12 \\
4 \\
8\end{array}$ \\
\hline \multicolumn{6}{|l|}{ 20: Others } \\
\hline $\begin{array}{l}5 \text { Before panproctocolectomy } \\
7 \text { After ileal or ileocaecal resection } \\
8 \text { No operation }\end{array}$ & $\begin{array}{l}1975-79 \\
1970-78\end{array}$ & $\begin{array}{l}61 \cdot 8 \\
41 \cdot 8 \\
42 \cdot 1\end{array}$ & $\begin{array}{l}2 \\
3 \\
3\end{array}$ & $\begin{array}{l}5 \\
5 \\
5\end{array}$ & $\begin{array}{l}5 \\
1 \\
1\end{array}$ \\
\hline
\end{tabular}

*Time from operation to study: 1 year-four patients. 1-3 years-six patients. 6, 7, 8 years-three patients.

ANORECTAL MANOMETRY

Evaluation of anorectal function was by measurement of the resting and squeeze anal canal pressures and an assessment of rectal capacity. Anal pressures were measured at $1,2,3,4$, and $5 \mathrm{~cm}$ from the anal verge using a closed water filled balloon probe as previously described. ${ }^{6}$ The maximum resting pressure was recorded as the highest pressure in the anal canal at rest. The maximum squeeze pressure was the highest pressure recorded in the anal canal on voluntary contraction of the sphincters. Rectal capacity was evaluated by observing the symptomatic response to $20 \mathrm{ml}$ increments of air introduced slowly into the rectal balloon. ${ }^{7}$ The volume at which the balloon could no longer be tolerated or retained or which was associated with uncontrolled faecal discharge was termed the 'maximum tolerated volume'. We have used the maximum tolerated volume as a measure of rectal capacity, as it is both reproducible and correlates well with the degree of proctitis in Crohn's colitis. ${ }^{8}$

\section{RADIOLOGICAL ASSESSMENT}

In 40 patients a comparison was made between the maximum tolerated volume and a radiological assessment of rectal capacity on barium enema in the same year. The 20 patients who did not have an initial ileorectal anastomosis are included, as only 20 of the 33 ileorectal patients had had a barium enema examination in the same year as their studies of anorectal function. The radiographs were reviewed by one person (JRL) who was unaware of the manometric findings. The capacity of the rectum was graded as normal, abnormal, or severe contracture.

\section{Results}

CLINICAL OUTCOME OF ILEORECTAL ANASTOMOSIS

The results of colectomy and ileorectal anastomosis are summarised in Table 2. Of the 33 patients
Table 2 Outcome of ileorectal anastomosis

\begin{tabular}{|c|c|c|c|}
\hline & \multicolumn{3}{|c|}{ Ileorectal anastomosis } \\
\hline & $\begin{array}{l}\text { Assessed } \\
\text { after (13) }\end{array}$ & $\begin{array}{l}\text { Assessed } \\
\text { before (20) }\end{array}$ & Total \\
\hline \multicolumn{4}{|l|}{ Initial procedure } \\
\hline Ileorectal anastomosis alone & 11 & 13 & 24 \\
\hline $\begin{array}{l}\text { Ileorectal anastomosis and } \\
\text { loop ileostomy }\end{array}$ & 2 & 7 & 9 \\
\hline severe rectal disease & $(2)$ & $(2)$ & (4) \\
\hline to protect anastomosis & $(0)$ & $(5)$ & (5) \\
\hline \multicolumn{4}{|l|}{ Final state (Jan 1981) } \\
\hline $\begin{array}{l}\text { Functioning ileorectal } \\
\text { anastomosis }\end{array}$ & 9 & 11 & 20 \\
\hline $\begin{array}{l}\text { Still have a loop ileostomy } \\
\text { (severe rectal disease) }\end{array}$ & 2 & 2 & 4 \\
\hline Proctectomy & 2 & 7 & 9 \\
\hline
\end{tabular}

having an ileorectal anastomosis, four had a loop ileostomy for severe anorectal disease. All four still have their loop ileostomy and all are likely to require a protectomy for persistent disease in the anus or rectum. The five patients who had a loop ileostomy to protect the anastomosis have all had their stoma closed within six months of the initial operation leaving 29 patients for assessment. Of the 29 patients, nine have subsequently required a proctectomy for recurrent rectal or perianal disease leaving 20 who still have a functioning ileorectal anastomosis: of these, five have had further surgery (three for recurrence in the ileum, one laparotomy for adhesions, and one cholecystectomy). The outcome of patients studied before or after ileorectal anastomosis is summarised in Table 2.

Of the 20 patients with a functioning ileorectal anastomosis, all are continent, although four complain of urgency and three have to open their bowels at night. The frequency of defaecation ranges from once to six times a day (mean 3.6 per day) but only five patients open their bowels more than five times a day. 


\section{MANOMETRIC FINDINGS}

Patients with an ileorectal anastomosis

The results of anorectal manometry have been classified according to the outcome of operation (Table 3). The maximum resting pressure did not differ significantly between the three groups (Fig. 1). Similarly there was no significant difference in the maximum squeeze pressure between the groups (Fig. 2). The mean maximum tolerated volume in the four patients who still have a loop ileostomy was $81 \mathrm{ml}$ air and in the nine patients who subsequently had a protectomy was only $77 \mathrm{ml}$ air. By contrast, the mean maximum tolerated volume in the patients who still have a functioning ileorectal anastomosis was $294 \mathrm{ml}$ air. None of the patients with a functioning ileorectal anastomosis had a maximum tolerated volume less than $150 \mathrm{ml}$ compared with all of the patients with a

Table 3 Changes in anorectal function according to outcome of ileorectal anastomosis

\begin{tabular}{llll}
\hline & $\begin{array}{l}\text { Functioning } \\
\text { ileorectal } \\
(n=20)\end{array}$ & $\begin{array}{l}\text { Still with } \\
\text { loop } \\
\text { ileostomy } \\
(n=4)\end{array}$ & $\begin{array}{l}\text { Protectomy } \\
(n=9)\end{array}$ \\
\hline $\begin{array}{l}\text { Mean maximum resting } \\
\text { pressure }\left(\mathrm{cm} \mathrm{H}_{2} \mathrm{O}\right)\end{array}$ & $88 \cdot 2 \pm 31$ & $96 \cdot 0 \pm 19$ & $93 \cdot 4 \pm 13$ \\
$\begin{array}{c}\text { Mean maximum squeeze } \\
\text { pressure }\left(\mathrm{cm} \mathrm{H}_{2} \mathrm{O}\right)\end{array}$ & $225 \cdot 1 \pm 67$ & $204 \cdot 7 \pm 33$ & $184 \cdot 6 \pm 41$ \\
$\begin{array}{l}\text { Maximum tolerated volume } \\
\text { Maximum }\end{array}$ & $294 \cdot 0 \pm 36$ & $* 81 \cdot 2 \pm 41$ & $* 77 \cdot 1 \pm 24$ \\
\hline
\end{tabular}

*Compared with functional ileorectal anastomosis $\mathrm{P}<0.02$.

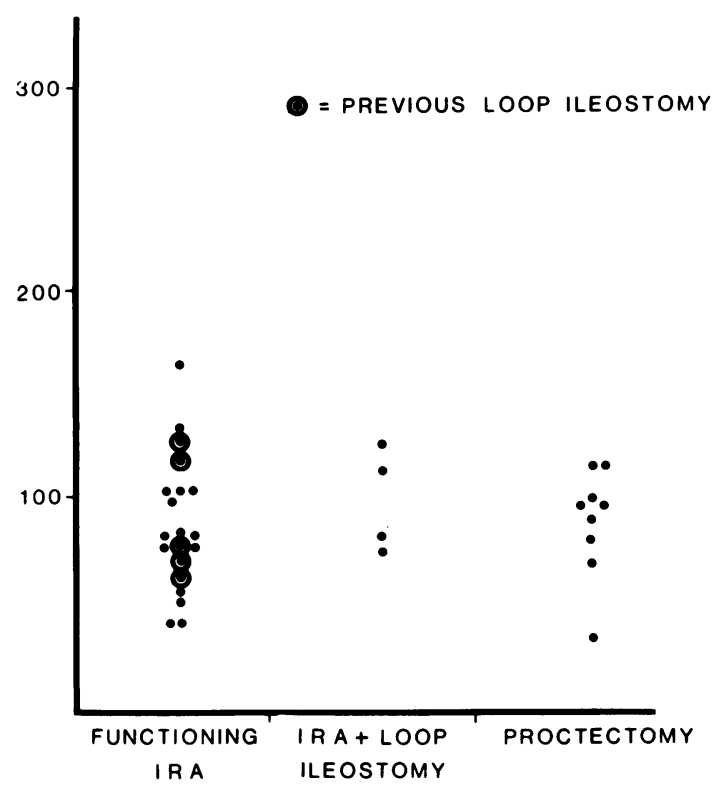

Fig. 1 The maximum resting pressures in $\mathrm{cm} \mathrm{H}_{2} \mathrm{O}$ according to the final outcome of ileorectal anastomosis (IRA).

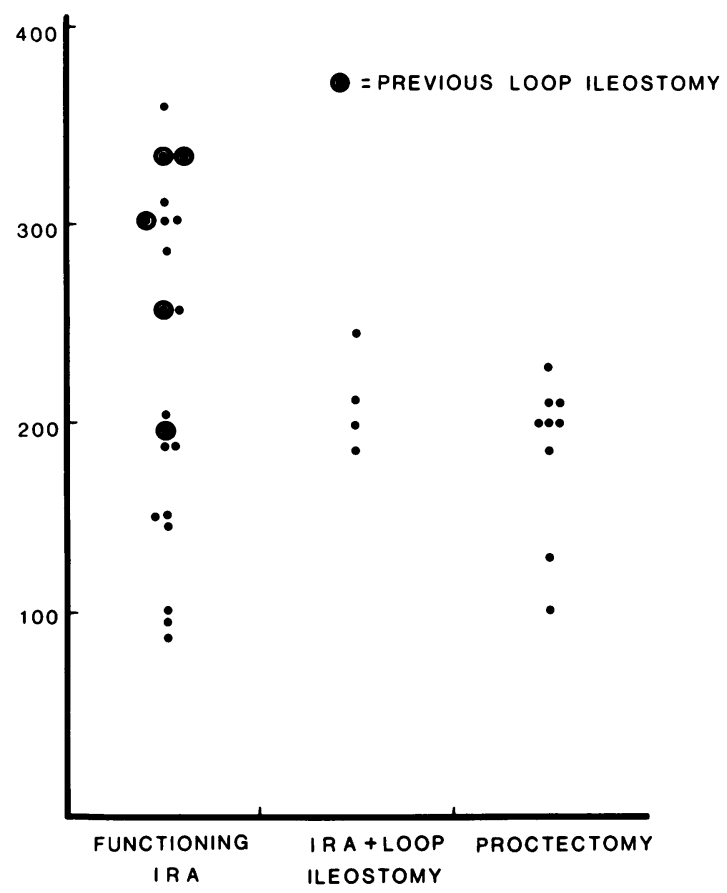

Fig. 2 The maximum squeeze pressures in $\mathrm{cm} \mathrm{H}_{2} \mathrm{O}$ according to the final outcome of ileorectal anastomosis (IRA).

loop ileostomy and eight of nine who have come to protectomy (Fig. 3). The difference in the maximum tolerated volume between those with a functioning ileorectal anastomosis and the patients with a stoma (persistent loop ileostomy or proctectomy) is statistically significant $(\mathrm{P}<0.02)$. Not all patients were investigated initially before their total colectomy and ileorectal anastomosis. Results have therefore been analysed separately but no differences were found between patients studied (Table 4).

In the patients who still have a functioning ileorectal anastomosis six had a maximum tolerated volume less than $200 \mathrm{ml}$ air; of these three pass five or more stools a day $(50 \%)$, whereas in the 14 patients whose maximum tolerated volume was greater than $200 \mathrm{ml}$ air, only two pass five or more stools a day $(17 \%)$. Of the four patients with a functioning ileorectal anastomosis having urgency, three had a maximum tolerated volume of less than $250 \mathrm{ml}$ air.

\section{Patients without an ileorectal anastomosis}

There was no difference in the maximum resting pressure and the maximum squeeze pressure between the three groups of patients who did not have an ileorectal anastomosis. On the other hand, the 


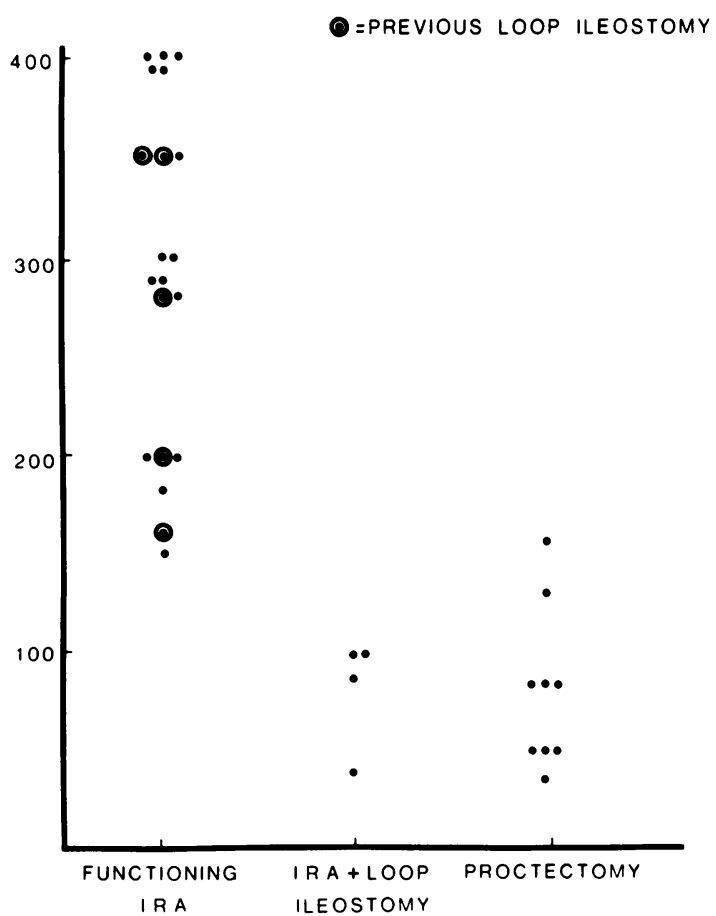

Fig. 3 The maximum tolerated rectal volume $(\mathrm{ml})$ according to the final outcome of ileorectal anastomosis (IRA).

Table 4 Comparison of anorectal function according to timing of ileorectal anastomosis

\begin{tabular}{lcc}
\hline & \multicolumn{2}{l}{ lleorectal anastomosis } \\
\cline { 2 - 3 } & $\begin{array}{l}\text { Assessed } \\
\text { after }(13)\end{array}$ & $\begin{array}{l}\text { Assessed } \\
\text { before (20) }\end{array}$ \\
\hline Maximum resting pressure & $86 \pm 17$ & $95 \pm 23$ \\
Maximum squeeze pressure & $220 \pm 36$ & $196 \pm 31$ \\
Maximum tolerated volume & $231 \pm 36$ & $199 \pm 41$ \\
\hline
\end{tabular}

maximum tolerated volume was less than $150 \mathrm{ml}$ air in all five patients studied before proctocolectomy. Only one of the seven patients studied after a previous ileal or ileocaecal resection had a maximum tolerated volume less than $150 \mathrm{ml}$, but this patient has marked proctitis. Only one of the eight patients who has not had an operation has a maximum tolerated volume less than $150 \mathrm{ml}$; this patient has extensive Crohn's colitis with anorectal disease but refuses a proctocolectomy.

Influence of follow-up on anorectal manometry To investigate the influence of time on anorectal manometry, six patients with a functioning ileorectal anastomosis have had studies repeated over two to four years (Fig. 4). There was very little
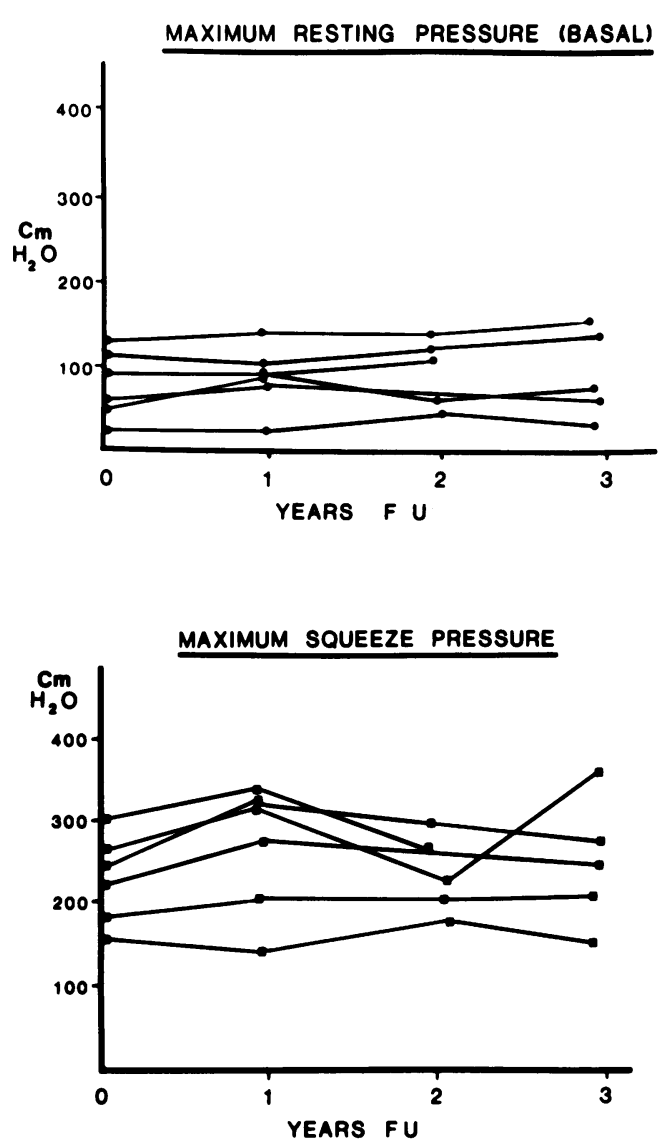

MAXIMUM TOLERATED VOLUME

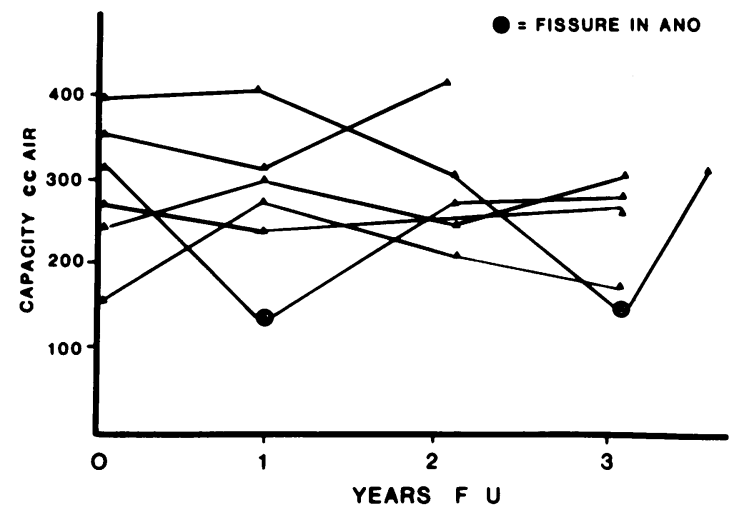

Fig. 4 Influence of duration of follow up on maximum resting and squeeze pressure $\left(\mathrm{cm} \mathrm{H}_{2} \mathrm{O}\right)$ and maximum tolerated volume $(\mathrm{ml})$ in six patients. 
change in the resting or squeeze pressures with time. However, in two patients there was a marked transient reduction in the maximum tolerated volume which was associated with relapse of a fissure in ano. When the fissure healed the maximum volume returned to its previous value.

\section{Radiological assessment of anorectal function}

Comparison with maximum tolerated volume The radiological assessment in rectal capacity was compared with the maximum tolerated volume and analysed according to whether the volume was 150 $\mathrm{ml}$ or less (Table 5). Thirteen of 40 patients had a volume equal to or less than $150 \mathrm{ml}$ but only seven were classified as having a severely reduced rectal capacity. In the 27 patients with a maximum volume greater than $150 \mathrm{ml}$ four were assessed as having a severely contracted rectum on radiography.

Findings in relation to outcome of ileorectal anastomosis Despite a poor correlation between maximum tolerated volume and the radiological assessment of rectal capacity, radiology was shown to be accurate in predicting a poor outcome after ileorectal anastomosis in the 20 patients having manometry and a barium enema assessment (Table 6). Of the seven patients judged to have a markedly reduced rectal capacity, six now have a stoma compared with only two of 13 patients who did not have radiological signs of a narrow rectum.

Table 5 Comparison between radiology and maximum tolerated volume

\begin{tabular}{llc}
\hline $\begin{array}{l}\text { Radiological assessment } \\
\text { of rectal capacity }\end{array}$ & $\begin{array}{l}\text { Maximum tolerated } \\
\text { volume }\end{array}$ \\
\cline { 2 - 3 } & $<150 \mathrm{ml}$ air $>150 \mathrm{ml}$ air \\
& $(13)$ & $(27)$ \\
\hline Severely reduced & 7 & 4 \\
Abnormal & 2 & 3 \\
Normal & 4 & 20 \\
\hline
\end{tabular}

Table 6 Radiological assessment and outcome of ileorectal anastomosis (20 patients studied before ileorectal anastomosis)

\begin{tabular}{lllll}
\hline $\begin{array}{l}\text { Assessment of } \\
\text { rectal capacity }\end{array}$ & & $\begin{array}{l}\text { Functioning } \\
\text { IRA }\end{array}$ & $\begin{array}{l}\text { Still have } \\
\text { loop ileostomy }\end{array}$ & Proctectomy \\
\hline Severely reduced & 7 & 1 & 2 & 4 \\
Abnormal & 4 & 3 & 1 & - \\
Normal & 9 & 8 & - & 1 \\
\hline
\end{tabular}

\section{Discussion}

The results of this study imply that measurement of the maximum tolerated volume might help to predict those patients with Crohn's colitis who are unlikely to benefit from a total colectomy and ileorectal anastomosis. Assessment of anal canal pressures was of no value in predicting the outcome of ileorectal anastomosis. Patients who had a maximum tolerated volume of less than $150 \mathrm{ml}$ have all required a stoma because of progressive anorectal disease. There was also a correlation between rectal capacity and the incidence of urgency and frequency of defaecation among the patients with a functioning ileorectal anastomosis.

Measurement of maximum tolerated volume is very simple and does not require any sophisticated equipment. Furthermore, repeated measurement in patients with Crohn's disease and an otherwise normal rectum is reproducible and correlates well with the degree of proctitis. ${ }^{9}$ In the small number of patients studied over the last four years, the maximum tolerated volume has remained relatively constant provided that there is no exacerbation of perianal disease. The maximum tolerated volume is much more variable, however, in ulcerative colitis, as it is related to the degree of proctitis, which is unstable. ${ }^{7}$ Assessment of the maximum tolerated volume should be made with a soft relatively thin rubber balloon in which large volumes may be accommodated with a minimal rise in pressure. ${ }^{10}$ A condom mounted on a fine tube is suitable for this purpose. Assessment of maximum tolerated volume is painful, and sometimes embarrassing to the patient, although most prefer the examination to a barium enema. The measurement is, however, subjective and the patient may not retain the balloon if it is very uncomfortable.

We feel justified in including in this study 13 patients who had their anorectal manometry performed after ileorectal anastomosis. All 13 patients were in good health after their operations, 10 had been operated upon less than four years earlier and the remainder have had excellent longstanding results and have remained well for over 10 years. Furthermore, there was no difference in the anal pressures or the maximum tolerated volume in patients studied before or after operation.

Assessment of the maximum tolerated volume should not be the sole criterion for selecting patients for ileorectal anastomosis. It is obvious that certain patients are unsuitable for the procedure, if, for instance, the anal sphincter is damaged as a result of previous perineal surgery, extensive perianal disease, ${ }^{11}$ or if a patient has marked rectal involve- 
ment. ${ }^{12}$ In these circumstances a panproctocolectomy would usually be advised. Similarly, if a patient has extensive small bowel disease ileorectal anastomosis is not usually recommended. ${ }^{13}$ There is, however, a group of patients with relative rectal sparing where further objective assessment of the rectum would be helpful. The radiological assessment of rectal distensibility may be difficult unless a single radiologist with a standardised procedure conducts the examination. These results indicate that there is a poor correlation between radiology and the maximum tolerated volume. It should be noted, however, that the barium enema examinations were performed by a variety of radiologists and not all were double contrast studies. Despite these objections, the surgeon usually has to make a decision to preserve or remove the rectum in Crohn's disease according to radiographs undertaken by a variety of different techniques. It is therefore gratifying to report that, in spite of the various radiological techniques employed, severe contracture of the rectum proved to be extremely reliable in predicting the patients who did badly after ileorectal anastomosis.

Despite a high incidence of recurrence after ileorectal anastomosis for Crohn's colitis ${ }^{14-16}$ it is often advisable to offer young patients an operation which does not involve a permanent stoma during the early years of their adult life. Furthermore, many of the recurrences after this operation occur in the terminal ileum or just proximal to the anastomosis, so that the rectum can often be preserved. ${ }^{2}$ Selection of patients suitable for ileorectal anastomosis should be by barium enema, sigmoidoscopy, or rectal examination. If there has been an adequate assessment of rectal capacity by lateral views of the rectum during double contrast barium enema, patients should not be-advised to have an ileorectal anastomosis if there is severe contracture of the rectum. If the radiological assessment is inadequate, measurement of maximum tolerated volume by an air-filled balloon offers an additional means of selecting patients who appear to do well after ileorectal anastomosis in the short term at least.

We wish to thank Dr R N Allan, Dr P W Dykes, and Mr J Alexander-Williams for allowing us to study their patients. We are grateful to Miss K Chamley and Miss $\mathbf{J}$ Downs for assistance with the preparation of figures and for typing the manuscript.

\section{References}

${ }^{1}$ Lockhart-Mummery HF, Morson BC. Crohn's disease (regional enteritis) of the large intestine and its distinction from ulcerative colitis. Gut 1960; 1:87-93.

${ }^{2}$ Goligher JC. The outcome of excisional operations for primary and recurrent Crohn's disease of the large intestine. Surg Gynec Obstet 1979; 148:1-8

${ }^{3}$ Allan RN, Cooke WT. In: Bouchier IAD, ed. Recent advances in gastroenterology: inflammatory bowel disease. Edinburgh: Churchill Livingstone, 1980: $117-46$.

${ }^{4}$ Weterman IT, Pena AS. The long term prognosis of ileorectal anastomosis and proctocolectomy in Crohn's disease. Scand J Gastroenterol 1976; 11 :185-91.

${ }^{5}$ Turnbull RB. The surgical approach to the treatment of inflammatory bowel disease; a personal view of techniques and prognosis. In: Kirsner JB, Shorter RG, eds. Inflammatory bowel disease. Philadelphia: Lee and Febiger 1975:338-84.

${ }^{6}$ Arabi Y, Alexander-Williams J, Keighley MRB. Anal pressures in haemorrhoids and anal fissure. Am J Surg $1977 ; 134: 608-10$.

${ }^{7}$ Farthing MJG, Lennard-Jones JE. Sensibility of the rectum to distension and the anorectal distension reflex in ulcerative colitis. Gut 1978; 19:64-9.

${ }^{8}$ Buchmann P, Mogg GAG, Alexander-Williams J, Allan RN, Keighley MRB. Relationship of proctitis and rectal capacity in Crohn's disease. Gut 1980; 21:137-40.

${ }^{9}$ Keighley MRB, Fielding JWL. Result of treatment in 112 patients with persistent faecal incontinence. $\mathrm{Br} J$ Surg 1981. In press.

${ }^{10}$ Duthie HL. Anal continence. Gut 1971; 12:844-52.

${ }^{11}$ Alexander-Williams J, Buchmann P. Perianal Crohn's disease. Wld J Surg 1980; 4:203-7.

${ }^{12}$ Buchmann P, Westerman I, Keighley MRB, Pena SA, Allan RN, Alexander-Williams $J$. The prognosis of ileorectal anastomosis in Crohn's disease. $\mathrm{Br} J$ Surg $1981 ; 68: 7-10$.

${ }^{13}$ Glotzer DL, Gardiner RC, Goldman H, Hinrichs HR, Rosen H, Zetzel L. Comparative features and course of ulcerative and granulomatous colitis. $N$ Engl J Med $1970 ; 282: 582-5$.

${ }^{14}$ Greenstein AJ, Sachar DB, Pasternack BS, Janowitz HD. Reoperation and recurrence in Crohn's colitis and ileocolitis: crude and cumulative rates. $N$ Engl J Med 1975; 293: 685-93.

${ }^{15}$ Steinberg DM, Allan RN, Cooke WT, AlexanderWilliams $\mathrm{J}$. The place of ileorectal anastomosis in Crohn's disease. Aust N Z J Surg 1976; 40:49-54.

${ }^{16}$ Nugent FW, Weidenheimer MC, Meissner WA, Haggitt RC. Prognosis after colonic resection for Crohn's disease of the colon. Gastroenterology 1973; 65:398-402. 